\title{
COMPORTAMENTO DO FOGO EM DIFERENTES PERÍODOS E CONFIGURAÇÕES DE UMA PAISAGEM NO NORDESTE DE PORTUGAL
}

\section{FIRE BEHAVIOUR IN DIFFERENT PERIODS AND CONFIGURATIONS OF A LANDSCAPE IN NORTHEASTERN PORTUGAL}

\author{
Simone Rodrigues de Magalhães ${ }^{1}$ Carlos Antonio Alvares Soares Ribeiro ${ }^{2}$ \\ José Manuel Correia dos Santos Ferreira de Castro ${ }^{3}$ \\ Paulo Alexandre Martins Fernandes ${ }^{4}$ Carlos Alberto Rodrigues Loureiro da Silva ${ }^{5}$ \\ Helena Margarida Pires Pinheiro ${ }^{6}$ João Carlos Martins de Azevedo ${ }^{7}$
}

\begin{abstract}
RESUMO
Neste trabalho aborda-se a importância do planejamento do uso e ocupação do solo, e do manejo dos sistemas florestais na redução do perigo de incêndio, analisando-se o comportamento do fogo em relação às alterações na paisagem da Deilão, nordeste de Portugal. Foram utilizadas cadeias de Markov e modelos de autômatos celulares como metodologia para projetar a paisagem no futuro. FlamMap foi utilizado para simular o comportamento do fogo. De acordo com as métricas da paisagem obtidas no Fragstats, observouse que os cenários e projeções em Deilão têm uma tendência à simplificação da paisagem, o que pode facilitar a ocorrência de incêndios maiores e mais graves. A análise dos resultados indicou uma tendência ao aumento do perigo de incêndios na região, em grande parte, ocasionado pela expansão de plantações contínuas de florestas. Para evitar tais impactos, o manejo florestal e ordenamento da paisagem devem ser modificados a fim de se reduzir o acúmulo de materiais combustíveis.
\end{abstract}

Palavras-chave: cadeias de Markov; autômatos celulares; ecologia de paisagens, manejo florestal.

\section{ABSTRACT}

In this study, we discuss the importance of land use, land cover planning and forest stand management in fire hazard reduction, through the analysis of fire behavior in relation to landscape changes in Deilão, northeastern Portugal. Markov chains and cellular automata model were used to project future landscapes whose structures were quantified by landscape metrics. The FlamMap model was used to simulate fire behavior. According to landscape metrics from Fragstats, we observed that scenarios and projections in Deilão have a trend towards landscape simplification, which may facilitate the occurrence of larger, more severe fires.

1 Engenheira Florestal, Dr., Professora do Centro Universitário dos Planalto de Araxá, Av. Min. Olavo Drummond, 05 - São Geraldo, Araxá (MG), Brasil. simagalhaes@gmail.com

2 Engenheiro Agrícola, Dr., Professor Titular do Departamento de Engenharia Florestal, Universidade Federal de Viçosa, Av. Peter Henry Rolfs, s/n, CEP 36570-900, Viçosa (MG), Brasil. cribeiro@ufv.br

3 Engenheiro Florestal, Dr., Professor Adjunto do Departamento Ambiente e Recursos Naturais, Instituto Politécnico de Bragança, Escola Superior Agrária, Campus de Santa Apolónia, 5301-855 Bragança, Portugal. mzecast@ipb.pt

4 Engenheiro Florestal, Dr., Professor Associado do Centro de Investigação e de Tecnologias Agroambientais e Biológicas, Universidade de Trás-os-Montes e Alto Douro, Quinta de Prados, 5001-801 Vila Real, Portugal. pfern@utad.pt

5 Engenheiro Florestal, MSc., Investigador do Centro de Investigação e de Tecnologias Agroambientais e Biológicas, Universidade de Trás-os-Montes e Alto Douro, Quinta de Prados, 5001-801 Vila Real, Portugal. carlos.a.r.loureiro@gmail.com

6 Engenheira Florestal, MSc., Câmara Municipal de Bragança, Largo Forte São João de Deus s/n, 5300-263 Bragança, Portugal. helena.pinheiro@cm-braganca.pt

7 Engenheiro Florestal, PhD., Professor Coordenador, Departamento de Ambiente e Recursos Naturais (ESA), Centro de Investigação de Montanha (CIMO), Instituto Politécnico de Bragança, Campus de Santa Apolónia, 5300-253 Bragança, Portugal. jazevedo@ipb.pt

Recebido para publicação em 6/05/2013 e aceito em 27/08/2015 
The analyses indicate an increased fire hazard trend in the region, largely caused by the continuity of forest cover. To avoid such impacts, forest management and landscape plannig should be modified in order to reduce the accumulation of combustible materials.

Keywords: Markov chains; cellular automata; landscape ecology, forest management.

\section{INTRODUÇÃO}

O estudo do comportamento do fogo é importante para auxílio à tomada de decisão em atividades de manejo, tais como a execução de queimadas controladas e na proposição de estratégias de prevenção e combate aos incêndios. Neste tipo de estudos desenvolvem-se modelos para simular a propagação do fogo na paisagem, os quais combinam informações acerca dos principais fatores, tais como características do material combustível e sua distribuição espacial, diretamente relacionados com o seu comportamento (PYNE et al., 1996).

O arranjo espacial dos componentes que formam a paisagem tem grande influência na expansão potencial dos incêndios e, a prazo, no regime de fogo. Em um incêndio, o fogo desenvolve-se nos vários estratos de combustíveis presentes, dependendo da continuidade horizontal e vertical desses combustíveis (FERNANDES; REGO, 2010). A continuidade horizontal depende da heterogeneidade da paisagem, a qual tem sido estudada em experimentos com pequenas parcelas com depósito de uma cama de combustível. Nestes experimentos observou-se que, uma vez que a transferência de calor é reduzida pela descontinuidade do combustível, a propagação do fogo também é reduzida (PYNE et al., 1996). Em geral, a massa de combustível acumulada na paisagem pode ter menor importância que o seu arranjo espacial, se existirem lacunas que dificultem a transferência de calor (ROTHERMEL, 1972; FRANDSEN; ANDREWS, 1979). A heterogeneidade e arranjo espacial dos combustíveis alteram o tipo de fogo, que pode ser contra ou a favor da direção predominante do vento e a complexidade do padrão das áreas queimadas, cuja descontinuidade do combustível impede a queima de determinadas áreas ou se propaga por rotas menos diretas, as áreas atingidas podem tornar-se mais complexas (FINNEY, 2001).

A tipologia vegetal é outro fator importante a ser considerado no estudo do comportamento dos incêndios florestais. Cada tipo vegetacional produz um combustível distinto quanto à sua carga e estrutura. Tais características tornam certos tipos vegetacionais mais susceptíveis ao fogo que outros, o que reflete o padrão das áreas queimadas. Em Portugal, por exemplo, Nunes (2005) observou a predominância de incêndios em formações arbustivas seguidas de florestas.

Os efeitos da alteração da paisagem sobre o comportamento do fogo têm sido tratados na literatura. Moreira et al. (2001) relacionaram o aumento do número de incêndios com alterações na estrutura da paisagem no nordeste de Portugal. Índices de homogeneidade da paisagem foram positivamente correlacionados com a ocorrência de incêndios em Valência, Espanha (VEGA-GARCIA; CHUVIECO, 2006). Lloret et al. (2002) também encontraram similar tendência por meio de testes estatísticos com padrões da paisagem e dados de fogo na Catalunha, Espanha. Azevedo et al. (2011) relataram diminuição na heterogeneidade da paisagem, devido ao abandono da agricultura, e aumento nas condições favoráveis à ocorrência de incêndios maiores e mais graves ao longo do tempo na freguesia de França, em Portugal. No entanto, estudos quantitativos sobre estas questões são escassos no sul da Europa e, além desses, também são necessários estudos que permitam antecipar alterações na paisagem e os correspondentes efeitos econômicos e ambientais.

Analisar o comportamento do fogo em nível de paisagem é imprescindível para uma melhor compreensão dos incêndios e desenvolvimento de um manejo preventivo. Neste trabalho analisou-se o papel do planejamento no ordenamento da paisagem e do manejo florestal para reduzir a ocorrência de incêndios de grande dimensão e, consequentemente, os danos causados por estes. A análise da variação no comportamento do fogo no passado e sua projeção no futuro, conforme as alterações na paisagem, fornece subsídios para ações de manejo florestal que evitam ou diminuem os danos causados pelos incêndios. Neste sentido, este trabalho visou avaliar o efeito das alterações em uma paisagem, passadas e previstas para o futuro, do Nordeste de Portugal, sobre o comportamento do fogo e as características dos incêndios, possibilitando gerar alternativas de manejo florestal. 


\section{MATERIAL E MÉTODO}

\section{Área de estudo}

A freguesia de Deilão localiza-se no nordeste de Portugal, no concelho e distrito de Bragança, sendo parte constituinte da unidade bioclimática da Terra Fria Transmontana (AGROCONSULTORES; COBA, 1991). Possui uma área de 4.197 ha e apresenta elevada importância para a conservação da natureza, integrando o Parque Natural de Montesinho (PNM) e o Sítio PTCON0002 - Montesinho/Nogueira da Rede Natura 2000.

Os cursos de água de regime torrencial que percorrem a freguesia de Deilão são afluentes do Rio Sabor, o qual pertence à bacia hidrográfica do Rio Douro (PINHEIRO, 2009). O relevo é ondulado, variando em altitude entre 600 e $900 \mathrm{~m}$, sendo a altitude máxima igual a $958 \mathrm{~m}$, junto ao povoamento de Deilão (PINHEIRO, 2009). O tipo climático na área de estudo é de Terra Fria de Planalto, segundo a classificação bioclimática adaptada por Agroconsultores e Coba (1991). Na região predominam os cambissolos úmbicos e dístricos, segundo a Carta de Solos do Nordeste de Portugal de Agroconsultores e Coba (1991). No fundo dos vales surgem pequenas unidades de solo de aluvião onde usualmente se estabelecem prados permanentes, os lameiros (PINHEIRO, 2009). A ocupação do solo distribui-se por áreas agrícolas, florestas, formações arbustivas, aglomerados urbanos e massas de água (PINHEIRO, 2009).

\section{Cartografia do uso e ocupação do solo}

As cartas de uso e ocupação do solo foram elaboradas a partir de fotointerpretação de coberturas aerofotográficas de 1958, 1968, 1980, 1992 e 2006, seguindo a classificação descrita pelo Instituto Geográfico Português (CAETANO et al., 2006). Cada unidade homogênea de uso e cobertura do solo foi delimitada e classificada em ambiente SIG. Obtiveram-se, desta forma, dados espaciais relativos ao uso e ocupação do solo na freguesia de Deilão para as datas indicadas anteriormente. A metodologia seguida encontra-se descrita em detalhe em Pinheiro (2009).

\section{Projeção da paisagem futura}

O modelo CA-Markov do programa IDRISI, versão Kilimanjaro foi utilizado para predizer a distribuição espacial do uso e ocupação do solo, recorrendo a uma coleção de mapas de aptidão do solo. $O$ modelo CA-Markov agrega os benefícios da série temporal e espacial das projeções das cadeias de Markov com metodologias de autômatos celulares (CA), adequando as mudanças de uso do solo aos efeitos de fatores naturais, sociais e econômicos (SANG et al., 2011). Este método exige que a coleção de imagens dos diferentes anos $(1958,1968,1992,2006)$ possua as mesmas classes e códigos de uso e ocupação do solo. Assim, as classes foram reagrupadas de forma que todas as cinco imagens utilizassem os mesmos códigos (Tabela 1). A classe área queimada foi identificada apenas nas imagens de 1992 e 2006. Não sendo possível o seu agrupamento com outra classe, esta foi redistribuída em classes diferentes por meio da ferramenta Assign, considerando as classes vizinhas e o uso do solo no ano de 2010 observado em imagens obtidas pelo satélite SPOT5, sensor HRG com resolução espacial de 2,5 m.

A análise das cadeias de Markov fornece uma matriz de probabilidades de transição entre classes de uso do solo referentes ao presente, tendo por base uma comparação com a distribuição de usos do solo de uma data anterior. Dessa forma, considerou-se como presente a situação descrita na imagem de 2006, que foi utilizada como referência nas comparações com aquelas obtidas nos anos de 1992, 1980, 1968 e 1958.

Para representação espacial dos resultados da análise de Markov, utilizou-se um modelo de autômatos celulares (Cellular Automata), baseado em um filtro de contiguidade. Na essência, este filtro aplica um fator de ponderação espacialmente explícito para cada classe, considerando, a dependência espacial entre os dados. O filtro de contiguidade foi aplicado a uma série de mapas de aptidão do território para cada uma das classes de uso e ocupação do solo. Estes mapas foram elaborados com base nos fatores condicionantes desta aptidão, os quais foram desenvolvidos segundo uma metodologia adaptada de Bernardes (2005). Os mapas de aptidão do terreno foram obtidos por meio do método de agregação por critérios múltiplos 
TABELA 1: Classes de uso e ocupação do solo identificadas na freguesia de Deilão e agrupadas em nível de menor detalhe.

TABLE 1: Low-resolution level of land use/cover classes of Deilão parish.

\begin{tabular}{|c|c|c|}
\hline Classe de uso do solo & Código & Classes agrupadas \\
\hline $\begin{array}{c}\text { Territórios } \\
\text { artificializados }\end{array}$ & 1 & Aglomerado urbano/Instalações agrícolas/ Áreas em construção \\
\hline Áreas agrícolas & 2 & $\begin{array}{l}\text { Culturas anuais de sequeiro/ Vinha/ Pomar/ Olivais/ Lameiros/ Sistemas } \\
\text { culturais e parcelares complexos/ Agricultura com espaços naturais/ SAF } \\
\text { de castanheiro/ SAF de castanheiro com resinosas }\end{array}$ \\
\hline Florestas & 3 & $\begin{array}{c}\text { Florestas de azinheira/ Florestas abertas de azinheira/ Florestas de } \\
\text { pinheiro-bravo/ Folhosas/ Florestas abertas de pinheiro-bravo/Novas } \\
\text { plantações/ Vegetação esparsa }\end{array}$ \\
\hline Formações arbustivas & 4 & $\begin{array}{c}\text { Estevais densos/ Estevais pouco densos/ Giestais densos/ Giestais pouco } \\
\text { densos/ Urzais densos/ Urzais pouco densos }\end{array}$ \\
\hline
\end{tabular}

denominado Combinação Linear Ponderada (Weighted Linear Combination - WLC), implementada no programa IDRISI. Os fatores considerados como condicionantes desta aptidão foram: declividade, altitude, distância em relação à aldeia, distância em relação aos cursos de água, dimensão da parcela, frequência de incêndios e índice de resistência (número de vezes que o pixel pertenceu à determinada classe de uso e ocupação do solo). Por meio do Processo Analítico Hierárquico (Analytic Hierarchy Process - AHP) atribuiu-se a importância relativa de cada fator (SAATY, 2000). Esta técnica hierarquiza os fatores por meio de comparações paritárias e determina a importância relativa de cada fator na decisão final. Obtiveram-se, assim, projeções para a paisagem de Deilão para 2020, 2032, 2044 e 2054.

\section{Caracterização da paisagem}

A estrutura da paisagem foi descrita quantitativamente por meio de métricas calculadas no programa Fragstats, versão 3.3 (MCGARIGAL; MARKS, 1995). Foram utilizados mapas de uso e ocupação do solo no nível de menor detalhamento, considerando-se quatro classes: territórios artificializados, áreas agrícolas, florestas e formações arbustivas.

Como métricas ao nível da paisagem calcularam-se: SHDI - Índice de Diversidade de Shannon, SIDI - Índice de Diversidade de Simpson, SHEI - Índice de Equitabilidade de Shannon, e SIEI - Índice de Equitabilidade de Simpson. As métricas ao nível da classe calculadas foram: NP - Número de Manchas, ED - Densidade de Borda (m.ha-1), LSI - Índice de Forma da Paisagem, LPI - Índice da Maior Mancha (\%), ENN-MN - Distância Euclidiana Média ao Vizinho Mais Próximo (m), e COHESION - Índice de Coesão.

\section{Análise do comportamento do fogo}

O modelo FlamMap versão 3 foi utilizado para analisar o comportamento do fogo na paisagem de Deilão nos anos descritos com base em observação da área de estudo (1958, 1968, 1980, 1992 e 2006), bem como nas condições projetadas para a mesma área no futuro $(2020,2032,2044$ e 2054). Inicialmente foram elaborados mapas com as características do terreno da área de estudo, dos combustíveis, da cobertura de copas e dos ventos na região. As características do terreno utilizadas foram declividade, altitude e orientação das encostas obtidas a partir do modelo digital do terreno. Os modelos de combustíveis foram atribuídos às classes de uso e ocupação do solo, correspondendo ao nível de maior detalhe da cartografia de uso e ocupação do solo, segundo a classificação do USDA Forest Service (ANDERSON, 1982), com adaptações, que considera 13 modelos de combustível (Tabela 2). A atribuição de modelos de combustível à classe de uso do solo "Florestas de pinheiro-bravo/Folhosas/Florestas abertas de pinheiro-bravo/Novas plantações/ 
TABELA 2: Modelos de combustível atribuídos às classes de uso e ocupação do solo da freguesia de Deilão.

TABLE 2: Fuel models assigned land use/cover classes of Deilão parish.

\begin{tabular}{cc}
\hline $\begin{array}{c}\text { Modelo de } \\
\text { combustível }\end{array}$ & Classe de uso e ocupação do solo \\
\hline 99 & Aglomerado urbano/ Instalações agrícolas/ Áreas em construção \\
1 & Vinha/ Pomar/ Olivais; Sistemas culturais e parcelares complexos \\
2 & Lameiros; Agricultura com espaços naturais/ SAF de castanheiro/ SAF de castanheiro \\
com resinosas
\end{tabular}

Em que: ${ }^{1}=$ modelo de combustível atribuído à classe de uso e ocupação do solo 8, nos anos 1980, 1992, 2006, 2020, 2032, 2044 e 2054; ${ }^{2}$ = modelo de combustível atribuído à classe de uso e ocupação do solo 8, nos anos 2020, 2032, 2044 e 2054; ${ }^{3}=$ modelo de combustível atribuído à classe de uso e ocupação do solo 8, nos anos 1958 e 1968.

Vegetação esparsa" (classe 8) considerou o contexto social e as políticas florestais à época, uma vez que tais considerações estão intimamente relacionadas com a distribuição e o volume de combustíveis.

O percentual de cobertura de copas foi estabelecido segundo as características da vegetação. Foram também utilizadas informações referentes ao estrato florestal, sendo determinada a altura total da formação florestal, a altura da base da copa e a densidade aparente da copa segundo o tipo florestal presente nas classes de uso e ocupação do solo (Tabela 3).

Utilizando-se o programa WindNinja 2.0.3 foram criados arquivos referentes à velocidade e à direção do vento conforme a variação na topografia. Estabeleceu-se como direção predominante Leste, uma vez que estes ventos se caracterizam como quentes e secos estando, portanto, associados às condições extremas para ocorrência de incêndios na região. A altura utilizada foi de $10 \mathrm{~m}$ e a velocidade de $20 \mathrm{~km} \cdot \mathrm{h}^{-1}$, o que caracteriza ventos fortes para a região.

Nas simulações efetuadas no FlamMap, atribuiu-se a umidade dos combustíveis mortos segundo o diâmetro do material. Neste trabalho, foram utilizados valores padrão de umidade em combustível vivo e morto para condições sinópticas extremas (Tabela 4).

Os parâmetros obtidos no FlamMap e analisados neste trabalho foram: intensidade da frente de fogo $\left(\mathrm{kW} \cdot \mathrm{m}^{-1}\right)$, velocidade de propagação $\left(\mathrm{m} \cdot \mathrm{min}^{-1}\right)$ e atividade de fogo e copas. Para a classificação do perigo de incêndio, reclassificaram-se os resultados referidos com base em Andrews e Rothermel (1982) e Alexander e Lanoville (1989). 
TABELA 3: Parâmetros dendrométricos associados à classe de uso e ocupação do solo.

TABLE 3: Dendrometric parameters associated with land use/cover classes.

\begin{tabular}{|c|c|c|c|c|c|}
\hline Classe de uso e ocupação do solo & Código & $\begin{array}{c}\text { Cobertura de } \\
\text { copas }(\%)\end{array}$ & $\begin{array}{c}\text { Altura das } \\
\text { árvores }(\mathrm{m})\end{array}$ & $\begin{array}{l}\text { Altura da base } \\
\text { da copa }(\mathrm{m})\end{array}$ & $\begin{array}{l}\text { Densidade das } \\
\text { copas }\left(\mathrm{kg} \cdot \mathrm{m}^{-3}\right)\end{array}$ \\
\hline $\begin{array}{l}\text { Florestas de azinheira/Florestas abertas de } \\
\text { azinheira }\end{array}$ & 7 & 60 & 7 & 1 & 1,7 \\
\hline $\begin{array}{c}\text { Florestas de pinheiro-bravo/Folhosas/Florestas } \\
\text { abertas de pinheiro-bravo/Novas plantações/ } \\
\text { Vegetação esparsa }\end{array}$ & 8 & 45 & 8 & 2 & 1,0 \\
\hline
\end{tabular}

TABELA 4: Umidade dos combustíveis mortos e vivos em relação ao percentual de peso seco para piroambientes meteorológicos extremos.

TABLE 4: Moisture content of dead and live fuels in relation to the percentage dry weight for extreme fire weather.

\begin{tabular}{ccc}
\hline Combustível & Diâmetro & Umidade (\% Peso seco) \\
\hline $1 \mathrm{~h}$ & $<6 \mathrm{~mm}$ & 4 \\
$10 \mathrm{~h}$ & $6-25 \mathrm{~mm}$ & 5 \\
$100 \mathrm{~h}$ & $25-75 \mathrm{~mm}$ & 6 \\
Herbáceas & - & 70 \\
Formações arbustivas & - & 70 \\
\hline
\end{tabular}

\section{RESULTADOS}

\section{Estrutura da paisagem}

Durante o período observado (1958 - 2006), a paisagem de Deilão sofreu alterações relevantes, especialmente quanto às áreas de floresta. No ano de 1958, as florestas tinham uma ocupação inexpressiva de menos de 1\% (33 ha), chegando em 2006 a um valor de 41\% (1.729 ha). As áreas agrícolas reduziram em torno de 29\%, passando de aproximadamente 53\% (2.229 ha) em 1958 para cerca de $37 \%$ (1.585 ha) em 2006. Da mesma forma, o percentual de ocupação das formações arbustivas passou de aproximadamente $45 \%$ (1.919 ha) para cerca de 20\% (855 ha). Os territórios artificializados, representados por áreas urbanas e infraestruturas, tiveram um crescimento de $67 \%$ em meio século, ocupando em torno de $0,33 \%$ (14 ha) em 1958 e cerca de $0,55 \%$ (24 ha) em 2006.

Mantendo-se as dinâmicas de alteração atuais, nas paisagens futuras, as florestas poderão ocupar quase $60 \%$ (2.504 ha) da área da freguesia no ano de 2054. As áreas agrícolas continuarão a decrescer chegando a ocupar aproximadamente $24 \%$ (998 ha), o que representa menos da metade da cobertura original de 1958 (53\%). Quanto às formações arbustivas, o percentual variou pouco em relação àquele observado no ano de 2006, ocupando cerca de 15\% (661 ha) da área em 2054. Da mesma forma, os territórios artificializados passarão a ocupar 0,72\% (30 ha) da área em 2054.

A diversidade da paisagem atingiu o seu valor máximo no ano de 1980, para o qual foram registrados os maiores valores dos índices de diversidade (SHDI $=1,1020$; SIDI $=0,6563$ ) e equitabilidade (SHEI $=$ 0,7949; SIEI = 0,8751). A partir do ano de 1992, os valores de diversidade e equitabilidade começaram a diminuir, gradualmente, porém, foram maiores que aqueles observados no ano de 1958 (SHDI = 0,7511; SIDI $=0,5084$; SHEI $=0,5418$; SIEI $=0,6778$ ). Em 2054, os índices obtidos foram: $\operatorname{SHDI}=0,9763$; $\mathrm{SIDI}=0,5619 ; \mathrm{SHEI}=0,7043 ; \mathrm{SIEI}=0,7492$.

A classe áreas agrícolas tornou-se mais fragmentada, o que pode ser observado pela análise dos índices para o nível de classes. O número de manchas (NP) aumentou continuamente durante o período 
em estudo, passando de 35, no ano 1958, para 104, no ano de 2054. A densidade de bordas (ED) diminuiu, passando de $57,95 \mathrm{~m} \cdot \mathrm{ha}^{-1}$, no ano de 1958 , para $41,51 \mathrm{~m} \cdot \mathrm{ha}^{-1}$, no ano de 2054 , sendo o maior valor $(61,05$ m.ha ${ }^{-1}$ ) registrado no ano de 2006 . O índice da maior mancha (LPI) reduziu, passando de $27,76 \%$ no ano de 1958 para $16,37 \%$ no ano de 2054 .

A classe que representa as florestas apresentou tendência à formação de grandes áreas contínuas, sendo que no ano de 1992 esta classe apresentou a menor distância entre as manchas ( $98 \mathrm{~m})$. No ano de 1958, esta classe era representada por apenas quatro manchas e a maior mancha não alcançou $1 \%$ da cobertura da paisagem (LPI $=0,57 \%$ ). No ano de 2006, foi registrado o maior número de manchas (NP $=46)$, bem como os maiores valores de densidade de borda $\left(\mathrm{ED}=45,28 \mathrm{~m} \cdot \mathrm{ha}^{-1}\right)$ e do índice de forma da paisagem ( $\mathrm{LPI}=11,40 \%$ ). Nas paisagens futuras, a continuidade entre as manchas foi evidenciada pelo decréscimo em seu número $(\mathrm{NP}=22)$, concomitante ao aumento do índice da maior mancha (LPI $=$ 41,23\%) e do índice de coesão (COHESION =99,51) registrados no ano de 2054.

A classe formações arbustivas tendeu a formar pequenos fragmentos, mais afastados entre si. $\mathrm{O}$ número de manchas correspondente aumentou, sendo os maiores valores registrados nos anos de $1992 \mathrm{e}$ $2044(\mathrm{NP}=67)$. A distância média entre as manchas passou de 93,24 m no ano de 1958 para 137,33 m no ano de 2054. Devido à redução da área ocupada por esta classe, os menores valores do índice de forma da paisagem e do índice da maior mancha foram registrados em $2054(\mathrm{LSI}=11,23$; LPI $=3,12 \%)$.

\section{Comportamento do fogo}

As simulações do comportamento do fogo na freguesia de Deilão produziram resultados muito distintos, acompanhando as alterações do uso do solo ao longo do tempo. Durante o período de 1958 a 2006 houve aumento expressivo das áreas com níveis de intensidade da frente de fogo mais elevados (Figura 1). No ano de 1958, a intensidade deste parâmetro se concentrava nas classes 3 e 4, correspondendo a aproximadamente $66 \%$ da área. A partir do ano de 1980, a intensidade da frente de fogo superior a 10.000 $\mathrm{kW} \cdot \mathrm{m}^{-1}$ passou a ser a de maior ocorrência na área correspondendo, em 2006 , a aproximadamente $43 \%$ da freguesia.

Nas paisagens projetadas para o futuro obtiveram-se valores diferentes para a intensidade da frente de fogo conforme o modelo de combustível atribuído à classe de uso do solo 8 , a qual se refere às florestas de pinheiro-bravo, folhosas, florestas abertas de pinheiro-bravo, novas plantações e vegetação esparsa. Ao se utilizar o modelo de combustível 4, a intensidade da frente de fogo atinge valores ainda maiores. Neste cenário, as classes 5 e 6 correspondem a $63 \%$ da área da paisagem (Figura 2A). Em contrapartida, o percentual ocupado pelas demais classes diminuiu continuamente. Ao se atribuir o modelo de combustível 6 à classe 8 , a intensidade do fogo decresceu (Figura 2B). No ano de 2054, a classe 3 predominou, ocupando aproximadamente $60 \%$ da área.

No período de 1958 a 2006, a velocidade de propagação do fogo, em média, decresceu (Figura 3). O percentual da área com velocidade de propagação superior a $30 \mathrm{~m} / \mathrm{min}$ (classe 6) diminuiu em aproximadamente 19\%. Por outro lado, o percentual de ocupação das classes 4 e 5 aumentou. A classe 4, que anteriormente ocupava apenas $5 \%$ da área, passou a ocupar $15 \%$, embora tenha alcançado $20 \%$ no ano de 1992.

Nas paisagens futuras, a velocidade de propagação também sofreu alteração em função do modelo atribuído à classe de uso e ocupação do solo 8 . Ao se utilizar o modelo de combustível 4 , a velocidade de propagação decresceu (Figura 4A). A classe 6 passou a ocupar 18\% da área, sendo que, na maior parte da freguesia, a velocidade de propagação variou entre 5 e $30 \mathrm{~m} \cdot \mathrm{min}^{-1}$, ou seja, predominaram as classes 4 e 5 . Ao se atribuir o modelo de combustível 6, obtiveram-se valores de velocidade de propagação ainda menores que aqueles obtidos com o modelo 4 (Figura 4B). A classe 3, que em 1958 ocupava apenas 0,4\% passou a representar $12 \%$ da área. O percentual de ocupação das classes 6 e 5 diminuiu e, em contrapartida, a classe 4 representou o maior percentual da área (cerca de 47\%) no ano de 2054.

No período de 1958 a 2006, a representatividade do fogo de copas aumentou expressivamente (Figura 5). No ano de 1958 foi observado fogo de copas em menos de 1\% da área, sendo a maior parte do território ocupada por fogo de superfície. Nos anos posteriores, houve aumento tanto do fogo passivo quanto do fogo ativo de copas. Em relação ao período citado (1958-2006), no ano de 1992 registrou-se o 


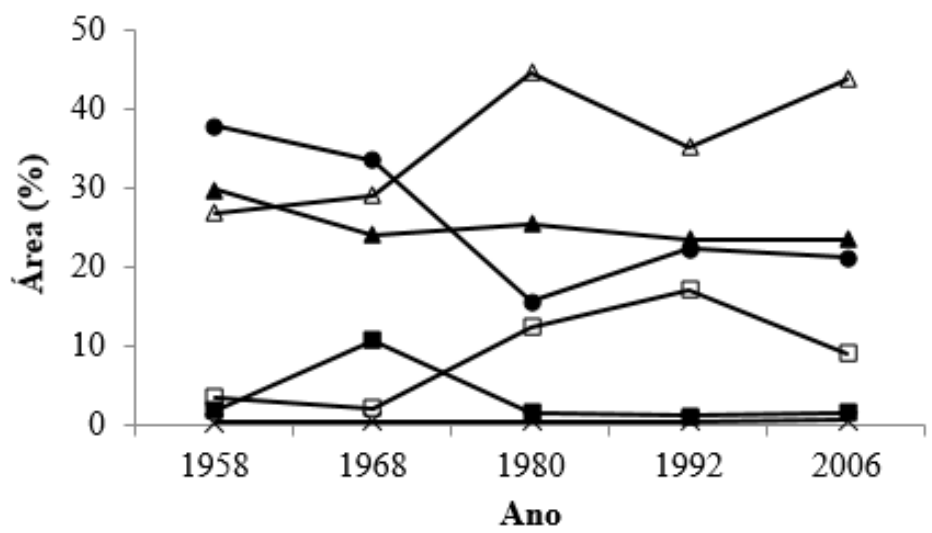

FIGURA 1: Distribuição percentual das classes de intensidade da frente de fogo $\left(\mathrm{kW} \cdot \mathrm{m}^{-1}\right)$ na área da freguesia de Deilão. $(\times)$ : classe $1(0) ;(\bullet)$ : classe $2(0-500) ;(\boldsymbol{\Lambda})$ : classe $3(500-2.000) ;(\bullet)$ : classe $4(2.000-4.000) ;(\square)$ : classe $5(4.000-10.000) ;(\Delta)$ : classe $6(>10.000)$.

FIGURE 1: Fireline intensity $\left(\mathrm{kW} \cdot \mathrm{m}^{-1}\right)$ classes distribution in Deilão parish. $(\times)$ : class $1(0)$; $(\mathbf{\square})$ : class $2(0$ $-500) ;(\mathbf{\Delta})$ : class $3(500-2.000) ;(\bullet)$ : class $4(2.000-4.000)$; (口): class $5(4.000-10.000)$; $(\Delta)$ : class $6(>10.000)$.
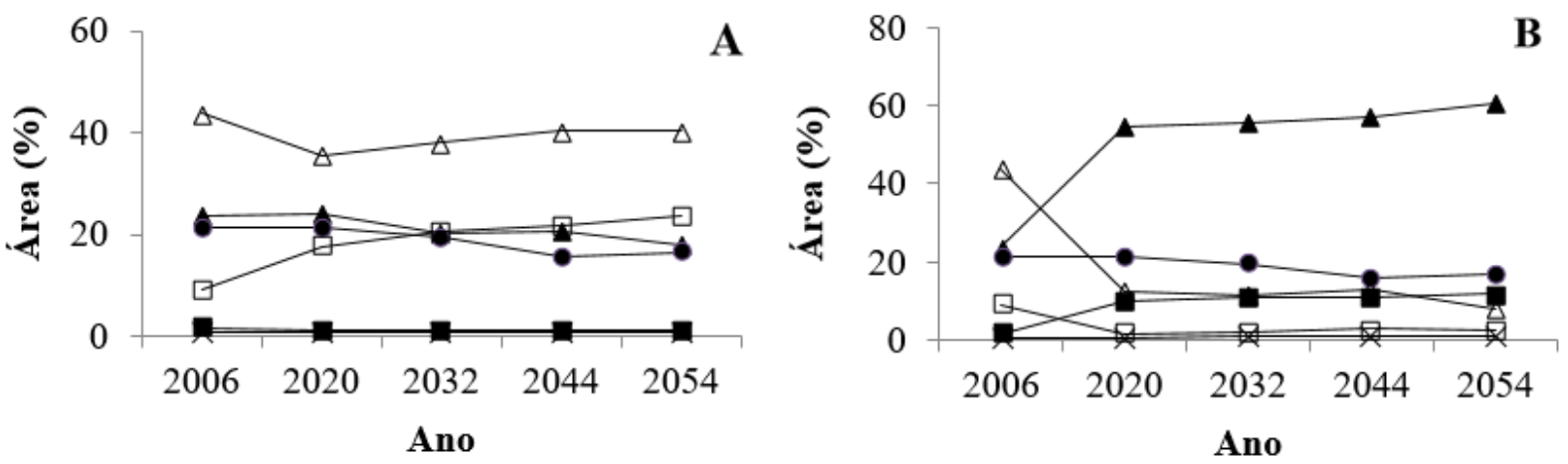

FIGURA 2: Distribuição percentual das classes de intensidade da frente de chamas $\left(\mathrm{kW} \cdot \mathrm{m}^{-1}\right)$ na área da freguesia de Deilão. A - classe de uso e ocupação do solo 8: modelo de combustível 4. B classe de uso e ocupação do solo 8: modelo de combustível 6. $(\times)$ : classe $1(0)$; (匹): classe 2 $(0-500) ;(\boldsymbol{\Delta})$ : classe $3(500-2.000) ;(\bullet)$ : classe 4 (2.000 - 4.000); (口): classe 5 (4.000 $10.000) ;(\Delta)$ : classe $6(>10.000)$.

FIGURE 2: Fireline intensity $\left(\mathrm{kW} \cdot \mathrm{m}^{-1}\right)$ classes distribution in Deilão parish. A - class use and land cover 8: fuel model 4. B - class use and land cover 8: fuel model 6. $(\times)$ : class 1 (0); ( $\mathbf{(})$ : class $2(0$ $-500) ;(\boldsymbol{\Delta})$ : class $3(500-2.000) ;(\bullet)$ : class 4 (2.000 - 4.000); (口): class 5 (4.000 - 10.000); $(\Delta)$ : class $6(>10.000)$.

maior percentual de área atingida por fogo passivo de copas. Quanto ao fogo ativo de copas, sua maior ocorrência foi no ano de 2006.

Nas paisagens futuras, a atividade do fogo de copas diferiu conforme o modelo de combustível atribuído à classe de uso e ocupação do solo 8, porém, a tendência observada foi semelhante. Ao se utilizar o modelo de combustível 4, o fogo de copas passivo aumenta expressivamente (Figura 6A). No ano de 1958, o fogo de copas representou cerca de $0,6 \%$ da área, chegando ao percentual de $57 \%$ no ano de 2054 . Em contrapartida, a ocorrência do fogo ativo de copas diminuiu drasticamente. A mesma tendência foi observada ao se atribuir o modelo de combustível 6, porém, o aumento da ocorrência do fogo de copas passivo foi menor em relação àquele observado com o modelo de combustível 4 (Figura 6B). Neste cenário, 


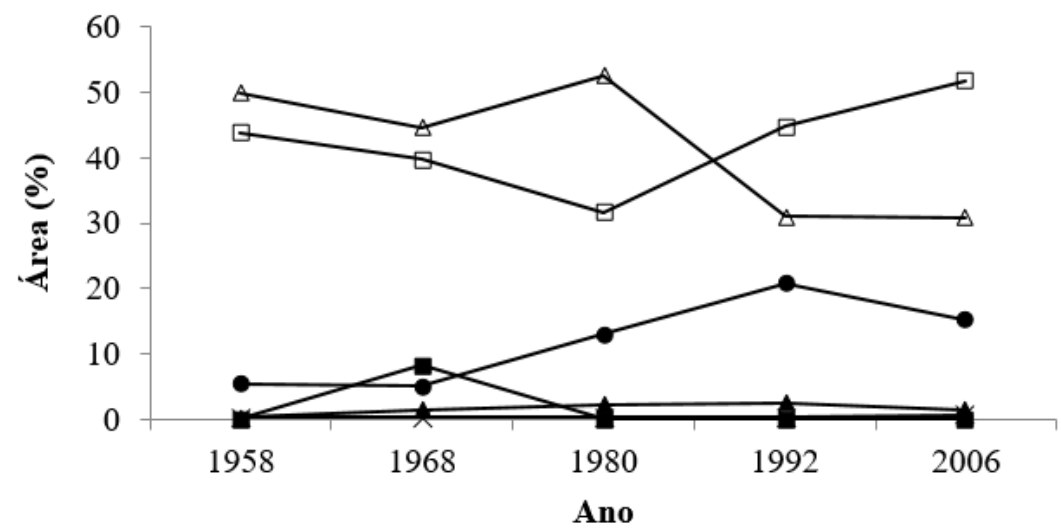

FIGURA 3: Distribuição percentual das classes de velocidade de propagação do fogo $\left(\mathrm{m} \cdot \mathrm{min}^{-1}\right)$ na área da freguesia de Deilão. $(\times)$ : classe $1(0) ;(\bullet)$ : classe $2(0-2) ;(\boldsymbol{\Delta})$ : classe $3(2-5) ;(\bullet)$ : classe 4 $(5-15) ;(\square)$ : classe $5(15-30) ;(\Delta)$ : classe $6(>30)$.

FIGURE 3: Rate of fire spread $\left(\mathrm{m} \mathrm{min}^{-1}\right)$ class distribution in Deilão parish. $(\times)$ : class $1(0)$; $(\mathbf{\square})$ : class 2 $(0-2) ;(\mathbf{\Delta})$ : class $3(2-5) ;(\bullet)$ : class $4(5-15) ;(\square)$ : class $5(15-30) ;(\Delta)$ : class $6(>30)$.
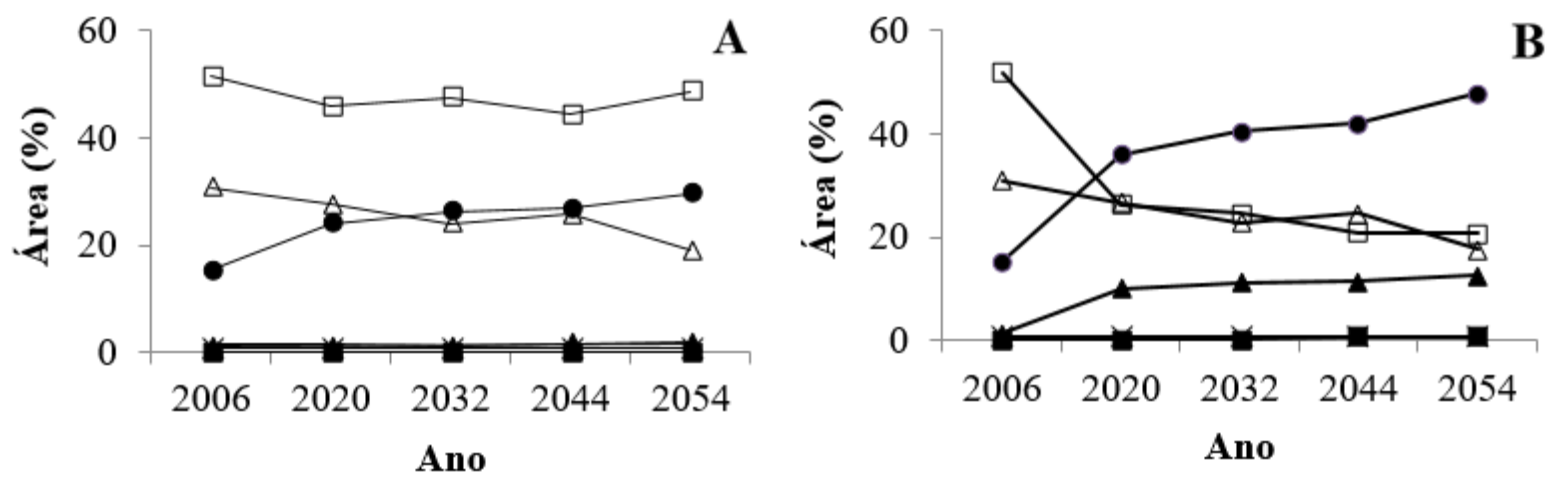

FIGURA 4: Distribuição percentual das classes de velocidade de propagação do fogo $\left(\mathrm{m}^{\mathrm{min}} \mathrm{min}^{-1}\right)$ na área da freguesia de Deilão. A - classe de uso e ocupação do solo 8: modelo de combustível 4. B classe de uso e ocupação do solo 8: modelo de combustível 6. $(\times)$ : classe $1(0)$; (ロ): classe 2 $(0-2) ;(\mathbf{\Delta})$ : classe $3(2-5) ;(\bullet)$ : classe $4(5-15) ;(\square)$ : classe $5(15-30) ;(\Delta)$ : classe $6(>30)$.

FIGURE 4: Rate of fire spread (m.min $\left.{ }^{-1}\right)$ classes distribution in Deilão parish. A - class use and land cover 8: fuel model 4. B - class use and land cover 8: fuel model 6. $(\times)$ : class $1(0) ;(\mathbf{\square})$ : class $2(0-$ 2); $(\mathbf{\Delta})$ : class $3(2-5) ;(\bullet)$ : class $4(5-15) ;(\square)$ : class $5(15-30) ;(\Delta)$ : class $6(>30)$.

o fogo de superfície continuou prevalecendo até o ano de 2054.

\section{DISCUSSÃO}

Este trabalho produziu informações importantes sobre a ocorrência e propagação do fogo, permitindo abordar a necessidade da gestão dos componentes da paisagem. Os resultados indicam que a freguesia de Deilão vem sendo florestada, enquanto ocorre redução de áreas agrícolas e da ocupação por formações arbustivas. Segundo Pinheiro (2009), as modificações na estrutura da paisagem de Deilão devemse principalmente ao envelhecimento da população, ao baixo rendimento dos produtos agrícolas, à política nacional de fomento florestal e ao incentivo ao reflorestamento por parte das políticas europeias. Nesta área, o abandono das terras ou a substituição de culturas anuais por culturas perenes, menos exigentes em mão 


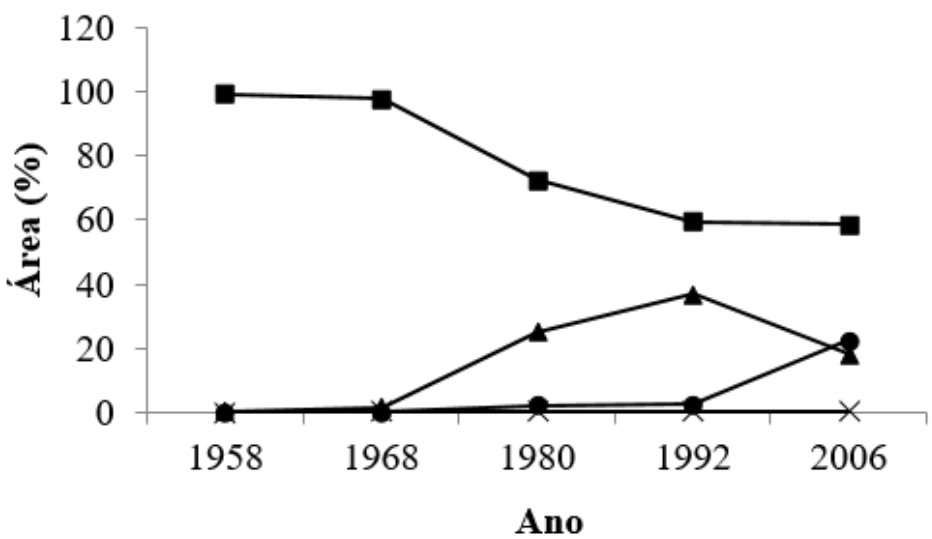

FIGURA 5: Distribuição percentual do tipo de fogo na área da freguesia de Deilão. $(\times)$ : fogo ausente; (๓): fogo de superfície; $(\boldsymbol{\Delta})$ : fogo passivo de copas; $(\bullet)$ : fogo ativo de copas.

FIGURE 5: Distribution of fire types in Deilão parish. $(\times)$ : absence of fire; $(\mathbf{\square})$ : surface fire; $(\mathbf{\Lambda})$ : passive crown fire; $(\bullet)$ : active crown fire.
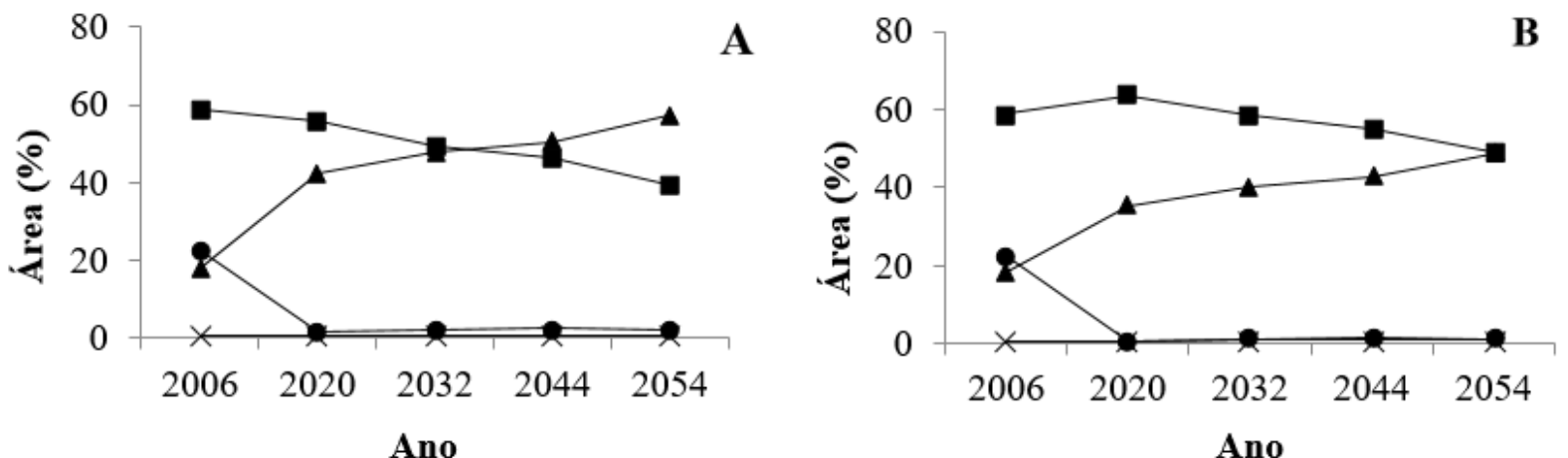

FIGURA 6: Distribuição percentual do tipo de fogo na área da freguesia de Deilão. A - classe de uso e ocupação do solo 8: modelo de combustível 4. B - classe de uso e ocupação do solo 8: modelo de combustível 6. (×): fogo ausente; (ロ): fogo de superfície; ( $\mathbf{\Delta}$ ): fogo passivo; $(\bullet)$ : fogo ativo.

FIGURE 6: Distribution of fire types in Deilão parish. A - class use and land cover 8: fuel model 4. B -class use and land cover 8: fuel model 6. $(\times)$ : absence of fire; $(\boldsymbol{\square})$ : surface fire; $(\boldsymbol{\Delta})$ : passive crown fire; $(\bullet)$ : active crown fire.

de obra, como os soutos (Castanea sativa) e os reflorestamentos, têm sido as principais responsáveis pela alteração da ocupação do solo.

$\mathrm{O}$ abandono da agricultura na freguesia reflete uma tendência geral relacionada com as características ambientais da região. Nas áreas de montanha, a agricultura apresenta limitações orográficas, estruturais e climáticas, as quais implicam barreiras à produção. Com isso, nestas áreas, a agricultura perdeu importância econômica e social nestas últimas décadas. Tal situação originou pouca rentabilidade, abandono de terras, perda de variedades autóctones. Por outro lado, a agricultura de montanha fornece alimentos de elevada qualidade com atributos ligados ao ambiente e ao sistema de produção. Além disso, a sociedade também reconhece os benefícios dos sistemas de agricultura sustentável da montanha que respeitam o ambiente. No entanto, o preço dos produtos e a baixa produção têm dificultado os agricultores destas regiões (HOPKINS, 2011).

O incremento da diversidade da paisagem até o ano de 1992 refletiu um aumento da área florestal 
à custa das formações arbustivas e das áreas agrícolas. Neste ano, o uso e ocupação do solo estavam bem distribuídos entre estas três classes. A partir de 2006, as florestas passaram a dominar a área da freguesia, o que reduziu a equitabilidade e, por consequência, a diversidade. Neste estudo, a diversidade é afetada diretamente pela equitabilidade, uma vez que a componente riqueza da diversidade não se altera. Esta tendência ao reflorestamento ocasionou tanto a redução quanto o agrupamento das áreas agrícolas, o que pode ser verificado pelo decréscimo da densidade de bordas, do índice da maior mancha e da distância entre as manchas desta classe.

$\mathrm{Na}$ freguesia de Deilão, a classe correspondente às formações arbustivas sofreu a maior redução, com tendência à formação de pequenos fragmentos distantes entre si. No entanto, embora os resultados indiquem a substituição da vegetação arbustiva por florestas, estas podem permanecer no sub-bosque.

A intensa implantação de áreas florestais gerou a formação de maciços florestais contínuos que podem ter facilitado a ocorrência de grandes incêndios florestais, como o que ocorreu em 2005. O fogo causou redução e fragmentação das áreas florestais, o que fica evidenciado pelo grande número de manchas e densidade de bordas observadas no ano de 2006.

Os cenários observados e projetados em Deilão indicam uma tendência à simplificação da estrutura da paisagem, a qual exerce influência sobre o comportamento dos incêndios na região. $O$ aumento da intensidade da frente de fogo é consequência direta do incremento da área florestal, uma vez que as florestas possuem alta carga de combustível. Além disso, as florestas podem abrigar um sub-bosque arbustivo, o que aumenta a carga e continuidade, vertical e horizontal, de combustíveis.

Por outro lado, a predominância de florestas provoca uma redução da velocidade de propagação do fogo. Nas áreas florestais, a velocidade de propagação pode ser menor em relação às áreas abertas. No interior das florestas, a velocidade do vento é menor, uma vez que as árvores atuam como quebra-vento.

$\mathrm{O}$ aumento da ocorrência de fogo de copas na freguesia de Deilão deve-se tanto ao aumento da área florestal quanto à sua distribuição espacial. No ano de 2006, a classe florestal estava mais fragmentada, no entanto, neste mesmo ano, o fogo de copas ativo foi superior ao fogo de copas passivo. Esta análise indica a presença de fragmentos florestais densos, uma vez que esta condição é necessária para a ocorrência do fogo de copas ativo.

A análise dos resultados obtidos indica uma tendência para o aumento do perigo de incêndios na região, possivelmente devido ao aumento da carga de combustível pelas alterações sociais e falta de gestão florestal. Caso o manejo florestal não seja modificado, a intensidade do fogo e a atividade do fogo em copas podem aumentar (modelo 4 atribuído à classe e uso e ocupação do solo 8), acarretando sérios prejuízos à região. Por outro lado, se forem tomadas medidas no sentido de diminuir a severidade do fogo, o cenário poderá ser diferente, assim como aquele representado nas simulações com o uso do modelo de combustível 6 atribuído às florestas nas paisagens futuras.

A distribuição espacial das características da frente de chamas - rapidez de propagação, dimensões, energia liberada - permite a elaboração de mapas de perigo de incêndio. Estes mapas permitem localizar regiões com maiores e menores riscos de ocorrências de incêndios de grandes dimensões. A combinação entre as informações obtidas em tais mapas e a análise do comportamento dos incêndios, ao longo das alterações da paisagem, fornecem informações importantes para o planejamento das ações de prevenção e combate. Assim, é possível minimizar os feitos negativos causados pelo fogo por meio da gestão dos elementos que compõem a paisagem. Tal gestão deve priorizar técnicas que reduzam o perigo de incêndio em nível de mancha, aumentem a heterogeneidade da paisagem e diminuam a conectividade entre coberturas inflamáveis. Neste sentido, podem ser realizadas operações como o corte manual ou mecânico do subbosque ou de componentes do arvoredo, o fogo controlado, o tratamento químico e o pastoreio dirigido (FERNANDES, 2006).

\section{CONCLUSÃO}

Caso não venham a ser alteradas as principais dinâmicas de uso do solo na freguesia de Deilão, é legítimo esperar um aumento da ocorrência de incêndios graves, com a substituição de área agrícola e área dominada por arbustos naturais, por plantações de florestas. A simplificação da paisagem, tende a aumentar a continuidade do material combustível e facilitar a ocorrência de grandes incêndios. A análise 
do comportamento do fogo em paisagens futuras fornece informações importantes sobre a necessidade de gerenciamento de componentes da paisagem, a fim de reduzir os impactos negativos causados pelo fogo. Para evitar tais impactos, o manejo florestal e ordenamento da paisagem devem ser modificados, evitando formações contínuas de florestas plantadas e reduzindo o acúmulo de materiais combustíveis.

\section{REFERÊNCIAS}

AGROCONSUlTORES; COBA. Carta dos solos, Carta do Uso Actual da Terra e Carta da Aptidão da Terra do Nordeste de Portugal. Memórias. Vila Real: Projecto de desenvolvimento rural integrado de Trás-os-Montes e Alto Douro, Universidade de Trás-os-Montes e Alto Douro, 1991. 114 p.

ALEXANDER, M. E.; LANOVILlE, R. A. Predicting fire behavior in the Black Spruce-Lichen Woodland fuel type of Western and Northern Canada. For Smith: Territorial Forest Fire Centre, 1989. $17 \mathrm{p}$.

ANDERSON, H. E. Aids to determining fuel models for estimating fire behavior. Ogden: Intermountain Forest and Range Experiment Station Ogden, 1982. 22 p.

ANDREWS, P. L.; ROTHERMEL, R. C. Charts for interpreting wildland fire behavior characteristics. Ogden: Intermountain Forest and Range Experiment Station, 1982. 21 p.

AZEVEDO, J. C. et al. Agriculture abandonment, land-use change and fire hazard in mountain landscapes in Northeastern Portugal. In: LI, C.; LAFORTEZZA, R.; CHEN, J. (Eds.). Landscape ecology in forest management and conservation: challenges and solutions for global change. New York: Springer, 2011. p. 329-351.

BERNARDES, F. G. A futura paisagem da Terra Fria Transmontana. 2005.92 f. Dissertação (Mestrado em Gestão e Conservação da Natureza) - Instituto Politécnico de Bragança, Bragança, 2005.

CAETANO, M.; NUNES, V.; ARAÚJO, A. Manual da carta de ocupação do solo de 2005 para Portugal continental. Lisboa: Instituto Geográfico Português, Grupo de Detecção Remota, 2006. 59 p.

FERNANDES, P. A. M. Silvicultura preventiva e gestão de combustíveis: opções e optimização. In: SANTOS, P. J. M. et al. (Eds.). Incêndios florestais em Portugal: caracterização, impactes e prevenção. Lisboa: ISA Press, 2006. p. 327-354.

FINNEY, M. A. Design of regular landscape fuel treatment patterns for modifying fire growth and behavior. Forest Science, Bethesda, v. 47, p. 219-228, 2001.

FRANDSEN, W.; ANDREWS, P. L. Fire behavior in nonuniforme fuels. Ogden: Intermountain Forest and Range Experiment Station, 1979. 34 p.

HOPKINS, A. Mountainous farming in Europe. In: SYMPOSIUM OF THE EUROPEAN GRASSLAND FEDERATION: GRASSLAND FARMING AND LAND MANAGEMENT SYSTEMS IN MOUNTAINIOUS REGIONS, 16., 2011. Proceedings... Irdning: Agricultural Research and Education Centre, 2011. p. 3-12.

LLORET, F. et al. Wildfires and landscape patterns in the Eastern Iberian Peninsula. Landscape Ecology, Dordrecht, v. 17, n. 8, p. 745-759, 2002.

MCGARIGAL, K.; MARKS, B. J. Fragstats: spatial pattern analysis program for quantifying landscape structure. Portland: Pacific Northwest Research Station, 1995. 122 p.

MOREIRA, F.; REGO, F. C.; FERREIRA, P. G. Temporal (1958-1995) pattern of change in a cultural landscape of northwestern Portugal: implications for fire occurrence. Landscape Ecology, Dordrecht, v. 16, n. 6 , p. $557-567,2001$.

NUNES, J. R. S. FMA ${ }^{+}$- Um novo índice de perigo de incêndios florestais para o estado do Paraná Brasil. 2005. 119 f. Tese (Doutorado em Ciências Florestais) - Universidade Federal do Paraná, Curitiba, 2005.

PINHEIRO, H. M. P. Alteração do uso do solo e stocks de carbono na freguesia de Deilão, Bragança. 2009. 59 f. Dissertação (Mestrado em Gestão de Recursos Florestais) - Escola Superior de Agrária, Instituto Politécnico de Bragança, Bragança, 2009.

PYNE, J. S.; ANDREWS, P. L.; LAVEN, R. D. Introduction to wildland fire. 2. ed. New York: John Wiley \& Sons, 1996. 808 p.

ROTHERMEL, R. C. A mathematical model for prediction fire spread in wildland fuel. Ogden: 
Intermountain Forest and Range Experiment Station, 1972. 40 p.

SAATY, T. L. Fundamentals of decision making and priority theory with the analytic hierachy process. Pittsburg: RWS Publications, 2000. 478 p.

SANG, L. et al. Simulation of land use spatial pattern of towns and villages based on CA-Markov model. Mathematical and Computer Modelling, Oxford, v. 54, p. 938-943, 2011.

VEGA-GARCIA, C.; CHUVIECO, E. Applying local measures of spatial heterogeneity to Landsat-TM images for predicting wildfire occurrence in Mediterranean landscapes. Landscape Ecology, Dordrecht, v. 21 , n. 4 , p. 595-605, 2006. 